(RESEARCH ARTICLE)

\title{
Continuous phenobarbital treatment and palmoplantar fibromatosis
}

\author{
Lachkar Adnane *, Elaissaoui Taha, Yacoubi Hicham and Najib Abdeljaouad \\ Orthopedic surgery department B, University Hospital Center Mohammed-VI, University Mohammed-I Oujda Morocco.
}

Publication history: Received on 29 January 2020; revised on 10 February 2020; accepted on 12 February 2020

Article DOI: https://doi.org/10.30574/wjarr.2020.5.2.0029

\begin{abstract}
Palmoplantar disease is a hyperproliferative disorder with dystrophic nodules in the superficial plantar and palmar fascia. It can be associated with other pathologies such as Lapeyronie's desease, diabetes, alcohol dependence or continuous phenobarbital treatment. We report the rare case of a pathological association made of Ledderhose's disease, Dupuytren's disease and barbiturates in an epileptic patient. Conservative treatment well conducted for more than 6 months is not satisfactory. A complete fasciectomy is performed with good functional results without recurrence. The association between epilepsy and palmoplantar fibromatosis is extremely rare. The role of barbiturates in mediating tissue growth factors would in theory explain this hyperproliferative disorder of the plantar fascia. The association between fibromatosis and cell growth mediators evokes new approaches aimed at modulating these cells for better therapeutic control.
\end{abstract}

Keywords: Ledderhose disease; Palmoplantar fibrosis; Epilepsy

\section{Introduction}

Ledderhose disease is an uncommon hyperproliferative condition. Its etiology is still unknown. It is responsible of dystrophic nodules growing on the superficial plantar aponeurosis [1, 2], It was described for the first time by the German doctor Georg Ledderhose in 1897 [3]. It's a very rare disease with an incidence lesser than $0.23 \%$. It mainly affects subjects between 30 and 50 years with a clear male predominance (sex ratio at 2:1) [5, 6]. It can affect both feet and can be associated with other disorders such as Dupuytren's, Laperyronie's, penile fibromatosis, diabetes, frozen shoulder or even alcohol addiction. In this paper we report a rare case associating Ledderhose and Dupyutren disorders (palmoplantar fibromatosis) in an epileptic patient under continuous phenobarbital treatment.

\section{Material and methods}

A 35 years old female, presented with a history of 5 years growing nodules on plantar aponeurosis of both feet and palmar aponeurosis of the right hand. The pain preventing here from standing for a long time. She had a negative medical family history. She was diagnosed for epilepsy at the age of 7 years old and was treated by continuous phenobarbital treatment.

The right foot presented two central firm nodules, the bigger one had a diameter of $2 \mathrm{~cm}$, the left foot presented a unique nodule with a diameter lesser than $1 \mathrm{~cm}$ (fig 1,2). These nodules were firm, painful and adherent to plantar fascia. On the right hand we found a fibrotic thickening of the palmar fascia associated with a central digital cord preventing the extension of the metacarpophalangeal and interphalangeal articulations of the thumb, the $4^{\text {th }}$ and the $5^{\text {th }}$ fingers (fig 3).

\footnotetext{
${ }^{*}$ Corresponding author

E-mail address: dr.lachkar@gmail.com
} 


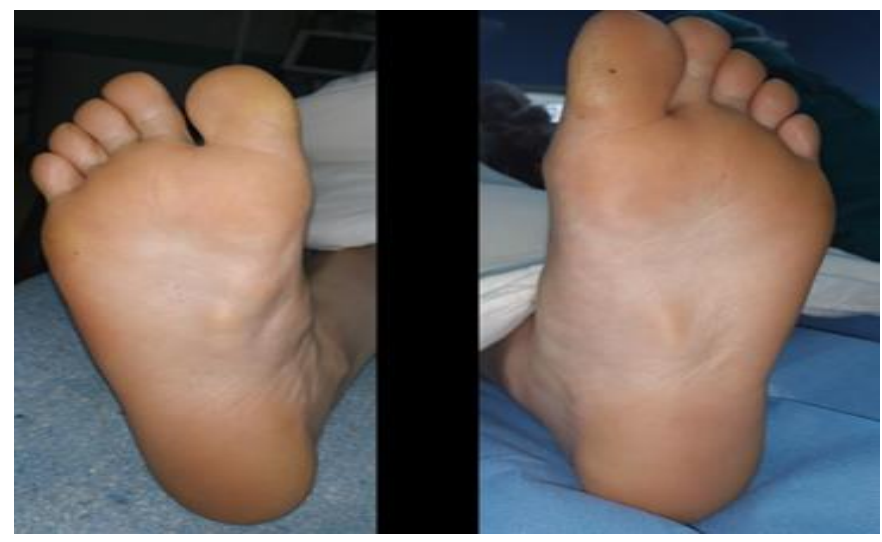

Figure 1 Clinical aspect of the feet (frontal view)

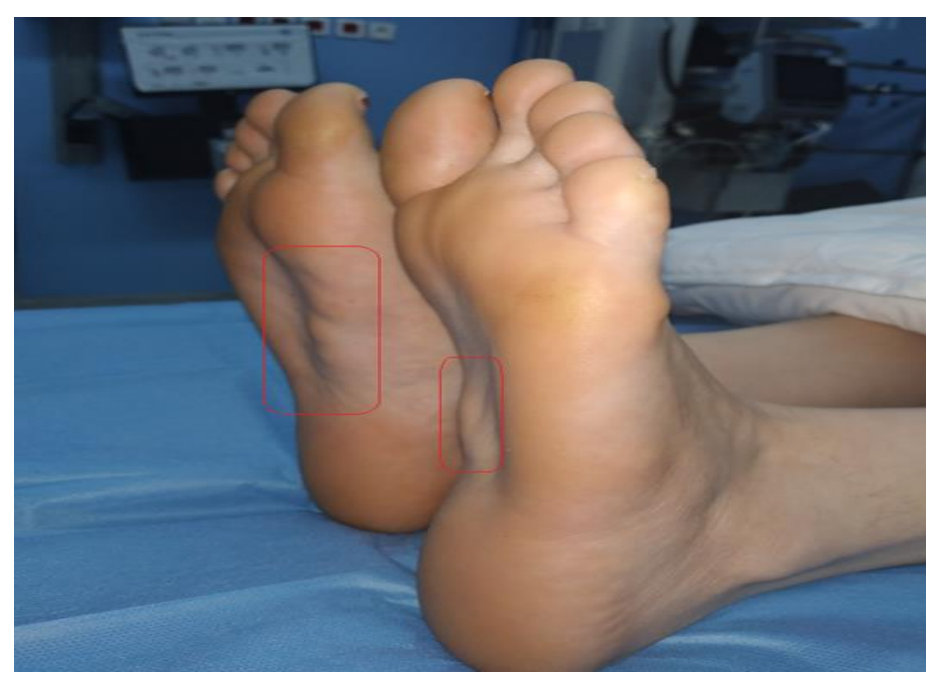

Figure 2 Clinical aspect of the feet (lateral view)

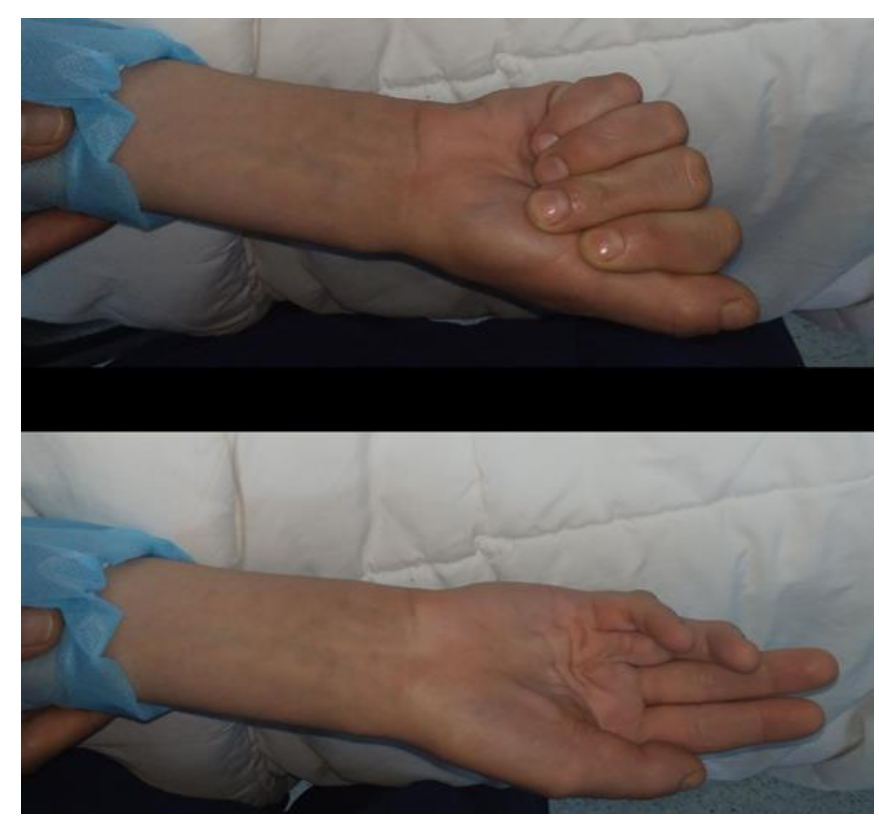

Figure 3 Clinical aspect of the right hand 


\section{Results}

The patient was diagnosed with palmoplantar fibromatosis and after a well conducted conservative treatment (nonsteroidal anti-inflammatory drugs, silicon insole, cryotherapy ...) over 6 months without any improvement, the surgical management was indicated (total plantar fasciectomy). An S-curved shaped incision of the plantar skin was made (fig 4), and careful dissection was performed to avoid undermining the skin and injuring the vascularity of the dermis, then the plantar fascia containing the nodules was isolated and excised (fig 5).

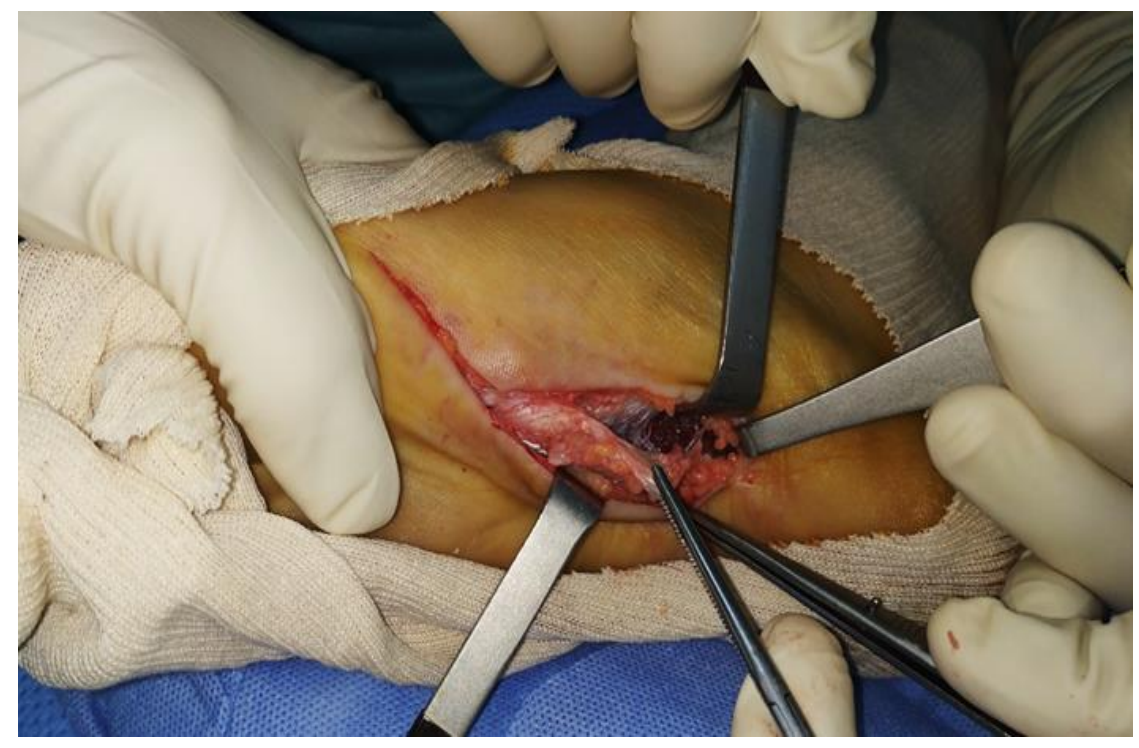

Figure 4 Aspect of the S-curved incision

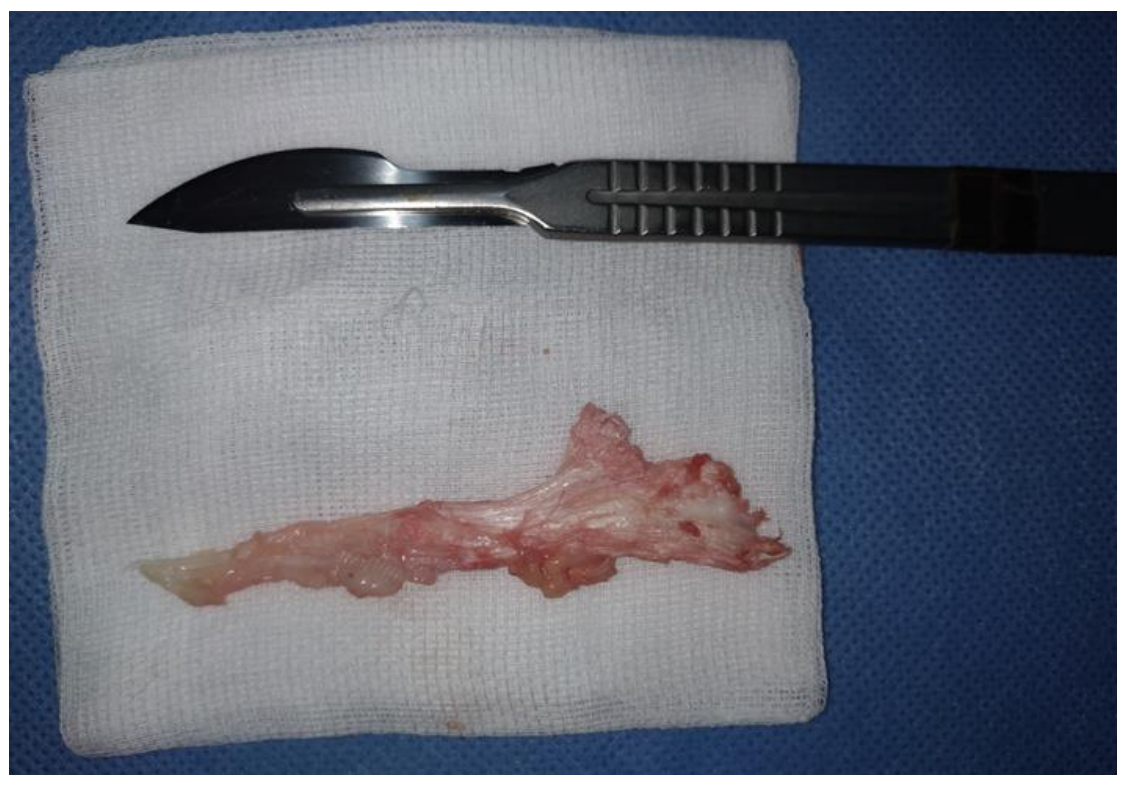

Figure 5 Plantar fascia excised

Finally, the skin was sutured without tension, the procedure was completed by the excision of the central palmar and the first ray cords by a longitudinal zig-zag approach associated with a VY flap (fig 6). 


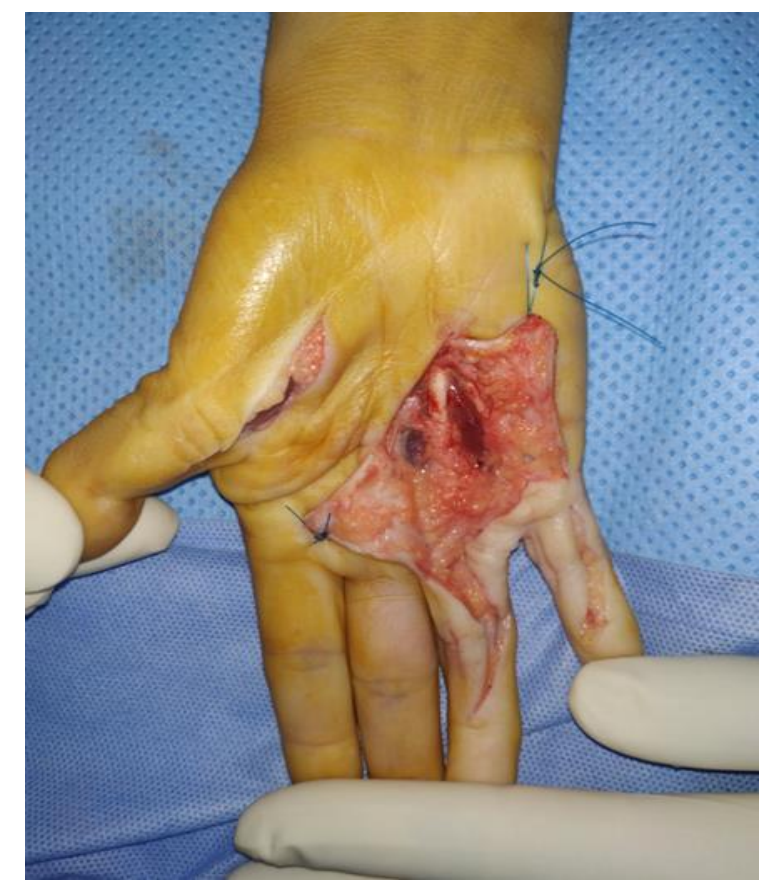

Figure 7 Excision of the central palmar and first ray cords

Weight bearing wasn't allowed for 3 weeks, until the wound was reevaluated and the sutures were removed. There were no complications. The diagnosis was confirmed through histological examination of the excised tissue. After a follow up of one year there was no complications or recurrences (fig 7).

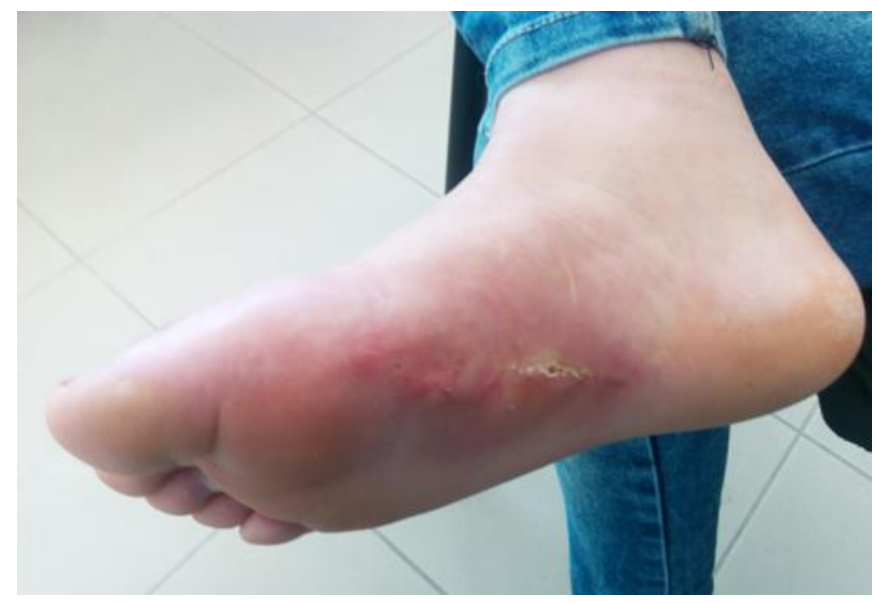

Figure 7 Final aspect (after 2 months)

\section{Discussion}

Ledderhose disease, or plantar fibromatosis, mainly affects middle-aged people (between 30 and 50 years old). However, some cases have been reported in children under the age of 16 [8]. Its prevalence and etiology are not always specified. It continues to appear on the list of rare diseases [11] affecting quality of life and causing severe functional disability [12]. The characteristic nodule of Ledderhose disease measures between 0.5 and $3.0 \mathrm{~cm}$ in diameter, it is most often located in the medial or central plantar fascia [1, 2, 5 ]. Typically, these are small, painless nodules that barely interfere with footwear or prolonged standing. The evolution, as slow as it is, is characterized by the increase in the diameter of knots which can become very painful and inflammatory in severe forms $[1,13,14]$.

The diagnosis of Ledderhose disease is mainly clinical [14]. The presence of one or more well defined nodules along the plantar fascia is pathognomonic of this disease. However, other differential diagnoses should be ruled out: The heel compression test can identify a calcaneal stress fracture; tarsal tunnel syndrome is identified by the presence of 
pain and numbness radiating to the plantar heel upon percussion of the posterior tibial nerve into the tarsal tunnel; finally, plantar fasciitis is characterized by excessive sensitivity of the medial border of the calcaneal tuberosity [13, $14]$.

Additional examinations are requested in cases of uncertain or doubtful diagnosis. In ultrasound we can morphologically visualize the "Comb sign": It is a hyperechoic aspect of the fibrous areas of the nodule on a background of hypoechoic cell matrix [15]. On MRI, these nodules appear as heterogeneous oval lesions included in the plantar fascia [16].

As for management, conservative treatment of Ledderhose disease is indicated for early forms of this pathology [14]. It is based on hygienic-dietary measures of plantar comfort such as orthopedic insoles. Other means of symptomatic treatment are proposed, such as nonsteroidal anti-inflammatory drugs, intra-nodular corticosteroid infiltrations, infiltrations by hyaluronidases and collagenases, localized radiotherapy or even extra-bodily shock waves [6, 14]. Nevertheless, surgery currently remains the only treatment providing satisfactory results. Three techniques have been used in the surgical management of plantar nodules: local excision, partial fasciectomy and total fasciectomy. Numerous studies have shown that local excision of the nodule has a very high recurrence rate (up to 100\%) [17 - 19]. The entire removal of the plantar fascia presents the lowest risk of recurrence (50 to 0\%) [17 - 19].

As in our patient, Ledderhose disease - rare as it is - often appears concomitantly with other hyperproliferative fibromatous syndromes such as Dupuytren's disease, La Peyronie's disease or the formation of keloids in a generalized way $[2,14,18]$. The association between epilepsy and palmoplantar fibromatosis was first described in 1941 by Lund where he noted an incidence of Dupuytren's disease reaching 50\% in 190 men and 25\% in 171 women with epilepsy in his series [20]. In 1969, James [21] argued that epilepsy and palmoplantar fibromatosis are both genetically determined and represent dominant linked genes; this has been refuted by other observations [22 - 25].

Finally, another hypothesis which could explain the association between administration of phenobarbital and palmoplantar fibromatosis involves the mediation of tissue growth factors. Indeed, the observation of Ghosh and McCandless [26] suggests that the acceleration of growth is manifest in children with temporal lobe epilepsy by the fact that phenobarbital can affect the release of corticotrophin, gonadotropin and antidiuretic hormone. These hypotheses broaden the therapeutic perspectives of Ledderhose disease. In this regard, treatment with synthetic nonsteroidal anti-estrogens such as tamoxifen has been suggested. In-vitro, observations have confirmed that the proliferative activity of fibroblasts exposed to tamoxifen has been reduced by inhibiting the expression of TGF- $\beta$ [27].

\section{Conclusion}

Ledderhose disease remains an exceptional pathological entity whose etiological mechanisms are not yet fully understood. Surgical excision of the plantar fascia always exposes to the non-negligible risk of recurrence. The association between fibromatosis and cell growth mediators suggests new approaches aimed at modulating the latter for better therapeutic control.

\section{Compliance with ethical standards}

\section{Acknowledgments}

Special acknowledgements for all the team of orthopedic surgery's department B, CHU Oujda - Morocco.

\section{Disclosure of conflict of interest}

None.

\section{Statement of ethical approval}

The present research work does not contain any studies performed on animals/humans subjects by any of the authors.

\section{Statement of informed consent}

Informed consent was obtained from all individual participants included in the study." 


\section{References}

[1] Gordon SD. (1964). Dupuytren's contracture: plantar involvement. Br J Plast Surg, 17, 412-413.

[2] Haedicke GJ and Sturim HS. (1989). Plantar fibromatosis: an isolated disease. Plast Reconstr Surg, 83(2), 296300 .

[3] Ledderhose G. (1897). Zur Pathologie der Aponeurose des Fusses und der Hand. Arch Klin Chir, 55, 694-712.

[4] Yost J, Winters T and Fett HC. (1955). Dupuytren's contracture: a statistical study. Amer J Surg, 90(4), 568-571.

[5] Donato RR and Morrison WA. (1996). Dupuytren's disease in the feet causing flexion contractures in the toes. J Hand Surg Br, 21(3), 364-366.

[6] Fausto de Souza D, Micaelo L, Cuzzi T and Ramos-E-Silva M. (2010). Ledderhose disease: an unusual presentation. J Clin Aesthet Dermatol, 3(9), 45-47.

[7] Palmieri A, Imbimbo C, Longo N, Fusco F, Verze P, Mangiapia F, Creta M and Mirone V. (2009). A first prospective, randomized, double-blind, placebo-controlled clinical trial evaluating extracorporeal shock wave therapy for the treatment of Peyronie's disease. Eur Urol, 56(2), 363-369.

[8] Burke FD, Proud G, Lawson IJ, McGeoch KL and Miles JN. (2007). An assessment of the effects of exposure to vibration, smoking, alcohol and diabetes on the prevalence of Dupuytren's disease in 97, 537 miners. J Hand Surg Eur, 32(4), 400-406.

[9] Bunker TD and Anthony PP. (1995). The pathology of frozen shoulder: a Dupuytren-like disease. J Bone Joint Surg Br, 77(5), 677-683.

[10] Paletta FX. (1981). Dupuytren's contracture. Am Fam Physician, 23, 85-90.

[11] Dürr HR, Krödel A, Trouillier H, Lienemann A and Refior HJ. (1999). Fibromatosis of the plantar fascia: diagnosis and indications for surgical treatment. Foot Ankle Int, 20(4), 13-17.

[12] De Palma L, Santucci A, Gigante A, Di Giulio A and Carloni S. (1999). Plantar fibromatosis: an immunohistochemical and ultrastructural study. Foot Ankle Int, 20(4), 253-257.

[13] Espert M, Anderson MR and Baumhauer JF. (2018). Current concepts review: plantar fibromatosis. Foot Ankle Int, 39(6), 751-757.

[14] Veith NT, Tschernig T, Histing T and Madry H. (2013). Plantar fibromatosis--topical review. Foot Ankle Int, 34(12), 1742-1746.

[15] Cohen BE, Murthy NS and Mckenzie GA. (2018). Ultrasonography of plantar fibromatosis: updated case series, review of the literature, and a novel descriptive appearance termed the "Comb Sign". J Ultrasound Med, 37(11), $2725-2731$.

[16] Mcnally EG and Shetty S. (2010). Plantar fascia: imaging diagnosis and guided treatment. Semin Musculoskelet Radiol, 14(3), 334-343.

[17] Reilly RM, Stern PJ and Goldfarb CA. (2005). A retrospective review of the management of Dupuytren's nodules. J Hand Surg Am, 30(5), 1014-1018.

[18] Carroll P, Henshaw RM, Garwood C, Raspovic K and Kumar D. (2018). Plantar fibromatosis: pathophysiology, surgical and nonsurgical therapies: an evidence-based review. Foot Ankle Spec, 11(2), 168-176.

[19] Aluisio FV, Mair SD and Hall RL. (1996). Plantar fibromatosis: treatment of primary and recurrent lesions and factors associated with recurrence. Foot Ankle Int, 17(11), 672-678.

[20] Lund M. (1941). Dupuytren's contracture and epilepsy. Acta Psychiatrica et Neurologica, 16, 465-492.

[21] James JIP. (1969). The relationship of Dupuytren's contracture and epilepsy. Hand 1(1), 47-49.

[22] Tripoli M, Cordova A and Moschella F. (2011). Dupuytren's contracture as result of prolonged administration of phenobarbital. Eur Rev Med Pharmacol, 15(3), 299-302.

[23] Critchley EM, Vakil SD, Hayward HW and Owen VM. (1976). Dupuytren's disease in epilepsy: Result of prolonged administration of anticonvulsants. J Neurol Neurosurg Psychiatry, 39(5), 498-503. 
[24] Broekstra DC, Groen H, Molenkamp S, Werker PMN and van den Heuvel ER. (2018). A systematic review and meta-analysis on the strength and consistency of the associations between Dupuytren disease and diabetes mellitus, liver disease, and epilepsy. Plast Reconstr Surg, 141(3), 367-379.

[25] Grazina R, Teixeira S, Ramos R, Sousa H, Ferreira A and Lemos R. (2019). Dupuytren's disease: where do we stand? EFORT Open Rev, 4(2), 63-69.

[26] Ghosh A and McCandless AE. (1975). Growth and anticonvulsant therapy. Lancet, 1, 858-859.

[27] Young JR, Sternbach S, Willinger M, Hutchinson ID and Rosenbaum AJ. (2019). The etiology, evaluation, and management of plantar fibromatosis. Orthop Res Rev, 11,1-7.

\section{How to cite this article}

Lachkar A, Elaissaoui T, Yacoubi H and Najib A. (2020). Continuous phenobarbital treatment and palmoplantar fibromatosis. World Journal of Advanced Research and Reviews, 5(2), 60-66. 